From the Section of Hematology/ Oncology and the Department of Health Studies, University of Chicago, Chicago, IL.

Submitted February 10, 2005; accepted April 26, 2005.

Supported by a grant from Berlex Pharmaceuticals and by National Cancer Institute grant No. CA 101337.

Authors' disclosures of potential conflicts of interest are found at the end of this article.

Presented in part at the 40th Annual Meeting of the American Society of Hematology, San Diego, CA, December 4-7, 2004.

Address reprint requests to Koen van Besien, MD, Section of Hematology/ Oncology, 5841 S Maryland Ave, Rm I 209, Chicago, IL 60637; e-mail: Kvbesien@uchicago.edu.

(C) 2005 by American Society of Clinical Oncology

0732-183X/05/2324-5728/\$20.00

DOI: $10.1200 / J C 0.2005 .15 .602$

\title{
Fludarabine, Melphalan, and Alemtuzumab Conditioning in Adults With Standard-Risk Advanced Acute Myeloid Leukemia and Myelodysplastic Syndrome
}

Koen van Besien, A. Artz, S. Smith, D. Cao, S. Rich, L. Godley, D. Jones, P. Del Cerro, D. Bennett, B. Casey, O. Odenike, M. Thirman, C. Daugherty, A. Wickrema, T. Zimmerman, R.A. Larson, and W. Stock

\section{$\begin{array}{llllllll}\text { A } & \text { B } & \text { S } & \text { T } & \text { R } & \text { A } & \text { C } & \text { T }\end{array}$}

\section{Purpose}

This prospective phase II study evaluated toxicity, relapse rate, progression-free survival, and overall survival after allogeneic transplantation and conditioning with fludarabine, melphalan, and alemtuzumab in patients with acute myeloid leukemia (AML) and myelodysplastic syndrome (MDS).

\section{Patients and Methods}

Fifty-two consecutive adults with AML and MDS were enrolled onto the study. Median age was 52 years (range, 17 to 71 years) and the majority of patients had high-risk disease, comorbidities, and/or modest reduction in performance status. Fifty-six percent of patients had unrelated or mismatched related donors.

\section{Results}

After a median follow-up of 18 months (range, 2 to 34 months), 1-year survival was $48 \%$ $(95 \% \mathrm{Cl}, 34 \%$ to $61 \%)$, progression-free survival was $38 \%(95 \% \mathrm{Cl}, 25 \%$ to $52 \%)$, relapse rate was $27 \%(95 \% \mathrm{Cl}, 15 \%$ to $40 \%)$, and treatment-related mortality was $33 \%(95 \% \mathrm{Cl}$, $20 \%$ to $46 \%$ ). The cumulative probability of extensive chronic graft-versus-host disease (GVHD) was only $18 \%(95 \% \mathrm{Cl}, 8 \%$ to $40 \%)$; extensive chronic GVHD was only observed in recipients of unrelated donor transplants. Performance score and disease status were the major predictors of outcome. High-risk disease (ie, active AML or MDS with $>5 \%$ blasts) or even modest decreases in performance status were associated with poor outcomes. Patients with standard-risk leukemia (first or second complete remission) or MDS $1<5 \%$ blasts) had excellent outcomes despite unfavorable disease characteristics.

\section{Conclusion}

Fludarabine and melphalan combined with in vivo alemtuzumab is a promising transplantation regimen for patients with $\mathrm{AML}$ or MDS and low tumor burden. For patients with active disease, this regimen provides at best modest palliation. Despite a low incidence of GVHD, transplantation is still associated with considerable nonrelapse mortality in patients with decreased performance status.

\section{J Clin Oncol 23:5728-5738. (C) 2005 by American Society of Clinical Oncology}

\section{INTRODUCTION}

Allogeneic hematopoietic stem-cell transplantation (SCT) offers the potential for prolonged disease-free survival for patients with advanced myelodysplastic syndrome (MDS) and acute myeloid leukemia (AML) who otherwise have a dismal prognosis. ${ }^{1-3}$ However, such patients are often older, have chemotherapy-resistant disease, have comorbidities, and lack related donors. With conventional total-body irradiation (TBI) or busulfan-based conditioning regimens followed by infusion of unmodified allografts, 
long-term survival rates range between $20 \%$ and 50\%. Adverse risk factors include more advanced disease, older age, the presence of comorbidities, and use of an unrelated donor. ${ }^{4-9}$ Modification of conditioning regimens and graft-versus-host disease (GVHD) prophylaxis have been investigated to improve outcomes in these high-risk populations.

In our previous exploratory studies, we evaluated the fludarabine plus melphalan regimen originally pioneered by the M.D. Anderson group (Houston, TX) and found it to be a reasonable alternative to TBI-containing regimens. ${ }^{10,11}$ The rationale for using high-dose melphalan for conditioning in allogeneic transplantation results from its convenience, its broad antitumor activity in hematologic malignancies, and its immunosuppressive effects, initially described in animal models, but subsequently confirmed by empirical clinical observations. $^{12,13}$ Fludarabine was added to this conditioning regimen because of its potent immunosuppressive effects and its potential synergism with alkylators. ${ }^{14}$ In our experience, the fludarabine and melphalan regimen allowed engraftment of matched-sibling cells, unrelated-donor cells, and even T-celldepleted haplo-identical cells.

Long-term survival of patients with advanced hematologic malignancies was similar to that after TBI-based conditioning. ${ }^{10}$ Conversely, we observed a considerable incidence of regimen-related morbidity and even mortality, with deaths as a result of mucositis, veno-occlusive disease/ sinusoidal obstruction syndrome, and cardiac toxicity. ${ }^{11}$ We suspected that regimen-related toxicity was compounded by the toxic effects of methotrexate used for GVHD prophylaxis. ${ }^{15-18}$ We also observed a high incidence of severe and sometimes fatal acute GVHD as well as extensive chronic GVHD that affected long-term outcomes, consistent with other studies of unmanipulated SCT, especially in the unrelated-donor setting. ${ }^{19}$ More recently, the addition of alemtuzumab to the fludarabine and melphalan regimen has been proposed as a reduced-toxicity conditioning for patients with advanced hematologic malignancies. $^{20,21}$ Alemtuzumab provides in vivo T-cell depletion and results in a low incidence of acute and chronic GVHD. ${ }^{22}$ We present outcome data for 52 consecutive patients with AML or MDS enrolled onto our phase II study of this regimen for advanced hematologic malignancies.

\section{PATIENTS AND METHODS}

The protocol was approved by the Institutional Review Board of the University of Chicago (Chicago, IL). All patients and donors provided written informed consent.

\section{Patients}

Patients with AML in first complete remission (CR1), second complete remission (CR2), or MDS with less than 5\% blasts were considered to have standard-risk disease; all others were considered to have high-risk disease. ${ }^{4}$ However, most of the standardrisk patients had unfavorable features and had a poor prognosis with conventional chemotherapy. In particular, patients with AML in CR1 were enrolled only if unfavorable prognostic features were present (unfavorable cytogenetics, high WBC count at diagnosis, resistance to initial induction regimen), and most patients with MDS had either unfavorable cytogenetics or a history of prolonged transfusion dependence. ${ }^{23}$

Additional eligibility criteria included Eastern Cooperative Oncology Group performance status $\leq 2$, bilirubin $\leq 2 \mathrm{mg} / \mathrm{dL}$, and creatinine less than $1.5 \times$ the upper limit of normal.

Comorbidities were assessed retrospectively using the Charlson comorbidity index, which assigns a score of 2 for a diagnosis of leukemia and tabulates additional points for a variety of comorbidities. ${ }^{24} \mathrm{~A}$ history of prior infections is not taken into account in the Charlson score. Performance status was routinely recorded for patients before transplantation.

\section{Donors and Stem-Cell Processing}

Acceptable donors were related or unrelated donors with no more than a one-antigen mismatch after considering HLA-A, B, C, and DR. Patients and donors for unrelated donor transplantation were typed for the HLA A, B, C, and DR loci by molecular sequencing techniques. Related donors underwent stem-cell mobilization using filgrastim subcutaneously $5 \mu \mathrm{g} / \mathrm{kg}$ bid for 5 consecutive days. Apheresis was started on day 5 and continued daily until at least $5 \times 10^{6} \mathrm{CD} 34$ cells/recipient $\mathrm{kg}$ were collected. For unrelated donors, granulocyte colony-stimulating factor mobilized blood stem-cell collection was requested. Bone marrow collections were accepted if such was the preference of the donor or of the collection center.

\section{Preparative Regimen}

Patients received fludarabine $30 \mathrm{mg} / \mathrm{m}^{2} / \mathrm{d}$ intravenously (IV), alemtuzumab $20 \mathrm{mg} / \mathrm{d}$ IV for 5 consecutive days (days -7 , $-6,-5,-4,-3$ ), and melphalan $140 \mathrm{mg} / \mathrm{m}^{2} / \mathrm{d}$ on day -2 (Fig 1). Acetaminophen, diphenhydramine, and methylprednisolone or hydrocortisone were given to prevent alemtuzumab toxicity.

\section{Post-Transplantation Immunosuppression}

Patients received tacrolimus from day -2 until day 100. Tacrolimus was initially administered IV and switched to oral administration on engraftment, targeting a trough level of 5 to 15 $\mathrm{ng} / \mathrm{mL}$. After day 100, tacrolimus was tapered over a period of 2 to 3 weeks, unless there was evidence of acute or chronic GVHD. Early withdrawal of immunosuppression was used if disease relapse occurred.

\section{Supportive Care and Growth Factors}

Patients were treated in rooms with high-efficiency, particulate-free air filters and with strict reverse isolation. They received filgrastim $5 \mu \mathrm{g} / \mathrm{kg} / \mathrm{d}$ subcutaneously, starting on day 1 after transplantation until a neutrophil count of more than $10 \times$ $10^{9} / \mathrm{L}$ had been reached.

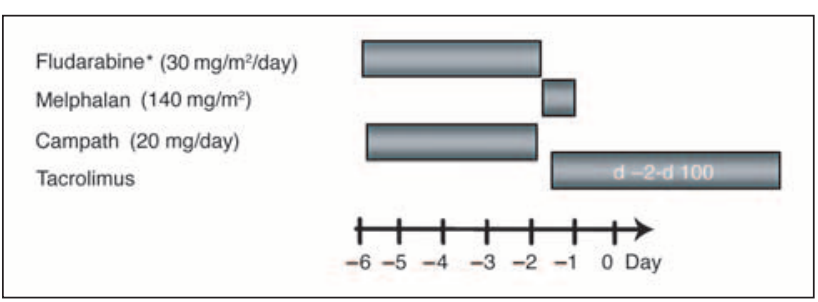

Fig 1. Conditioning regimen. 
Patients received levofloxacin $500 \mathrm{mg}$ or gatifloxacin 400 $\mathrm{mg} / \mathrm{d}$ orally (PO) until resolution of neutropenia. Most patients received fluconazole $200 \mathrm{mg} / \mathrm{d}$ until day 180 . Patients with a history of invasive fungal infection, or those considered at high risk for it, received voriconazole $200 \mathrm{mg}$ bid PO instead. Two trimethoprim/sulfamethoxazole double-strength tablets per day twice a week were administered from engraftment until 1 year after transplantation.

Antiviral prophylaxis was initially administered as previously described. ${ }^{25}$ All patients who were cytomegalovirus (CMV) positive or had a CMV-seropositive donor were given ganciclovir 5 $\mathrm{mg} / \mathrm{kg}$ from day -8 until day -3 . They then were given acyclovir $10 \mathrm{mg} / \mathrm{kg}$ every 8 hours IV until discharge. On discharge, acyclovir $800 \mathrm{mg}$ PO tid was continued until day 180. Subsequently, the policy was changed to include valacyclovir 2,000 $\mathrm{mg}$ qid from discharge until day 210 for all patients who were CMV positive or had a CMV-positive donor. ${ }^{26}$

Patients were screened weekly for CMV viremia until day 120 and treated with ganciclovir on detection of CMV viremia. Antifungal, antiviral, and Pneumocystis prophylaxis and screening for CMV viremia continued indefinitely for those with active GVHD or those receiving immunosuppressive treatment.

Irradiated and leukocyte-depleted blood products were administered to maintain a hemoglobin level greater than $8 \mathrm{~g} / \mathrm{dL}$ and platelet count greater than $10 \times 10^{9} / \mathrm{L}$. No attempt was made to provide CMV-negative blood products for CMV-negative transplant recipients; instead, CMV-negative donor/recipient pairs were screened weekly for CMV viremia. ${ }^{27}$

\section{Post-Transplantation Evaluation}

Disease relapse was defined as disease progression from the best response. Death without disease progression was considered transplantation related. Acute and chronic GVHD were scored and treated according to standard criteria. ${ }^{28}$

\section{Engraftment Analysis}

Bone marrow and/or peripheral-blood specimens were collected at approximately days 28, 100, 180 after transplantation. Donor and recipient cells were detected by quantitative analysis of informative microsatellite sequences of DNA as described previously. ${ }^{29}$

\section{Statistical Methods}

Progression-free survival (time to relapse or death as a result of any cause), overall survival, and cumulative probability of acute GVHD and extensive chronic GVHD were calculated using the Kaplan-Meier product-limit estimate and expressed as probabilities with a $95 \%$ CI. ${ }^{29,30}$ For GVHD, patients who died without GVHD were censored at the time of death, and cumulative probability at time $t$ was calculated as $1-\mathrm{KM}(t)$, where $\mathrm{KM}(t)$ is the Kaplan-Meier estimate of remaining event-free at time $t$. Cumulative incidence of disease progression with death before progression as the competing risk, ${ }^{31}$ and cumulative incidence of treatment-related mortality with non-treatment-related death as the competing risk were also calculated. (See Chappell ${ }^{32}$ or Klein $^{33}$ for a discussion of issues related to the use of $1-\mathrm{KM} v$ cumulative incidence.)

Univariate comparisons and multivariate analyses used Cox proportional hazards regressions. Parameters calculated in the univariate and multivariate analyses included disease status (standard risk $v$ high risk), age, performance status at transplantation (0 $v \geq 1)$, disease type (AML $v$ MDS), therapy-related leukemia versus no therapy-related leukemia, comorbidity score at transplantation $(2 v>2)$, prior transplantation $v$ no prior transplantation, and donor type (HLA-identical related donor $v$ antigen- mismatched related or unrelated donor). For the multivariate Cox models, independent variables with $P>0.1$ were excluded sequentially from the models. The relative risks and the associated $P$ values of the remaining variables are reported. All data were analyzed as of December 31, 2004.

\section{RESULTS}

\section{Patients}

From December 2001 until October 2004, 52 consecutive patients with AML or MDS were enrolled. Their characteristics are listed in Table 1. Median age at transplantation was 52 years (range, 17 to 71 years). Twenty patients had standard-risk disease and 32 had high-risk disease. There were nine patients with AML in CR1, four with AML in CR2, and seven with MDS. Among the nine patients with AML in CR1, two had therapy-related AML, four had AML with unfavorable cytogenetics, two had normal cytogenetics but hyperleukocytosis at diagnosis (90 $\times 10^{9} / \mathrm{L}$ and $200 \times 10^{9} / \mathrm{L}$, respectively), and one had a tetraploid karyotype and required two courses of chemotherapy to achieve CR1. Among the MDS patients, there were four therapy-related MDS with an international prognostic score (IPS) of 1.5 in three patients and 1 in one patient. ${ }^{23}$

\begin{tabular}{|c|c|c|}
\hline Characteristic & $\begin{array}{c}\text { No. of } \\
\text { Patients }\end{array}$ & $\%$ \\
\hline \multicolumn{3}{|l|}{ Age, years } \\
\hline Median & \multicolumn{2}{|c|}{52} \\
\hline Range & \multicolumn{2}{|c|}{$17-71$} \\
\hline Low tumor burden, standard risk & 20 & 38 \\
\hline MDS $<5 \%$ blasts & 7 & 13 \\
\hline AML CR1 & 9 & 17 \\
\hline AML CR2 & 4 & 7 \\
\hline High tumor burden (high risk) & 32 & 62 \\
\hline MDS $>5 \%$ blasts & 4 & 7 \\
\hline AML with active disease & 28 & 54 \\
\hline Therapy-related myeloid leukemia & 9 & 17 \\
\hline$P S \geq 1$ & 21 & 40 \\
\hline Prior fungal infection & 9 & 17 \\
\hline Significant comorbidity* & 15 & 29 \\
\hline Prior transplantation, autologous or allogeneic & 13 & 25 \\
\hline \multicolumn{3}{|l|}{ Type of donor } \\
\hline HLA-identical sibling & 23 & 44 \\
\hline Allele/antigen-mismatched relative & 4 & 8 \\
\hline Matched unrelated donor & 22 & 43 \\
\hline One allele/antigen-mismatched unrelated donor & 3 & 6 \\
\hline Donor and/or recipient CMV positive & $49 \ddagger$ & 94 \\
\hline
\end{tabular}

Abbreviations: MDS, myelodysplastic syndrome; $A M L$, acute myeloid leukemia; CR1, first complete remission: CR2, second complete remis-

sion; PS, performance status; CMV, cytomegalovirus.

*Charlson comorbidity index $>2$.

tOne antigen was mismatched in three patients; one allele and one antigen were mismatched in one patient (see text).

$\ddagger A$ total of 48 recipients were seropositive. There was only one seronegative recipient with a seropositive donor. 
Finally, three patients with transfusion-dependent refractory anemia with ring sideroblasts were included. Two of them had an IPS score of 0 and one had a score of 0.5 .

Among the 28 patients with high-risk AML, one was in a third remission, and one had a hypoplastic marrow after intensive reinduction within 2 weeks before transplantation; 26 patients had blasts in the bone marrow at the time of transplantation. Nineteen of the 26 also had circulating blasts (median, $2 \%$ of WBCs; range, $1 \%$ to $40 \%$ ). The four patients with high-risk MDS had more than $5 \%$ blasts in the bone marrow at transplantation and three of them also had between $1 \%$ and $4 \%$ circulating blasts. Their IPS scores were $1,1.5,1.5$, and 2 , respectively.

Fifteen patients had significant comorbidities as determined by the Charlson comorbidity index, 13 had experienced disease relapse after a prior transplantation, and 21 had a poor performance status (18 patients had a moderate decline [performance score $=1$ ] and three had a more substantial decline [performance score $>1$ ]). Nine patients had radiologic sequelae from prior fungal infections (eight of whom also had high-risk disease).

Twenty-seven patients received stem cells from related donors, including 23 HLA-identical sibling donors, three one-antigen-mismatched related donors, and one twoantigen-mismatched related donor. In the latter case, the second allele mismatch was detected only on sequencing after graft failure. Twenty-five patients had unrelated donors, of which 22 were molecularly matched at A, B, C, and $\mathrm{DR}$, but three had a one-antigen or one-allele mismatch at one of these loci. In all but three patients, the donors and/or recipients were positive for CMV.

\section{Engraftment}

Graft rejection was observed in two recipients of stem cells from related, HLA-mismatched donors. A female patient with transfusion-dependent refractory anemia with ring sideroblasts and hepatic fibrosis received a one-antigen-mismatched graft from her brother. After initial engraftment, she rejected the graft. She later failed to engraft after a second stem-cell infusion and died with aplasia. This patient case has been reported previously. ${ }^{34} \mathrm{~A}$ second patient with refractory AML, who received a two-antigenmismatched graft from his son (initially thought to be a one-antigen mismatch), experienced primary graft failure, and died with aplasia. On molecular typing, mismatches in both the $\mathrm{B}$ and $\mathrm{C}$ locus were found.

\section{Treatment-Related Deaths}

Including the two graft failures, there were 16 occurrences of treatment-related mortality, and nine of these occurred before day 100. The causes of death are listed in Table 2. Many of the treatment-related deaths occurred in patients with substantial comorbidities, and several may have been contributed to by prior treatment and/or comorbidities. Three deaths in recipients of unrelated donor transplantation were related to GVHD. There were no GVHD-related deaths in recipients of matched sibling transplants. Of interest, despite the inclusion of nine patients with a history of prior fungal infections, no deaths were a result of to fungal infection. One patient developed an anaphylactic reaction during conditioning, probably contributed by alemtuzumab. No other life-threatening reactions to alemtuzumab were observed during the course of this study, although fever and urticaria were common.

\section{GVHD}

The cumulative probability of grade 2 to 4 acute GVHD was $33 \%$ at 1 year ( $95 \%$ CI, $21 \%$ to $49 \%)$. Only four patients developed grade 3 to 4 acute GVHD, for a cumulative probability of $10 \%$ (95\% CI, $4 \%$ to $25 \%$ ). Five patients developed chronic GVHD, extensive in all cases, for a cumulative probability of chronic GVHD of $18 \%$ at 1 year (95\% CI, $8 \%$ to $40 \%$ ). All five patients with extensive chronic GVHD were recipients of unrelated donor transplants (Fisher's exact test, $P=.02$ ).

\section{Univariate and Multivariate Analysis of Outcomes}

The cumulative incidence of treatment-related mortality, cumulative incidence of relapse, progression-free survival, and overall survival are shown in Fig 2. Estimated rates at 100 days, 200 days, 1 year, and 2 years are listed in Table 3. With a median follow-up for survivors of 18 months (range, 2 to 34 months), 1-year survival is $48 \%$ ( $95 \%$ CI, $33 \%$ to $61 \%$ ), progression-free survival is $38 \%$ ( $95 \%$ CI, $25 \%$ to $52 \%$ ), and cumulative incidence of relapse is $32 \%$ ( $95 \%$ CI, $19 \%$ to $45 \%$ ). Cumulative incidence of treatment-related mortality is $17 \%(95 \% \mathrm{CI}, 9 \%$ to $29 \%)$ at 100 days, but reaches $33 \%$ (95\% CI, 20\% to $46 \%$ ) at 1 year.

In univariate Cox regression analyses (Table 4), disease status, age, performance score, and presence of comorbidities were significantly $(P \leq .05)$ associated with one or more outcomes. The relative risks and $P$ values of the remaining independent variables in the multivariate Cox regressions with stepwise model selection are listed in Table 5. Performance status was strongly associated with treatment-related mortality $(P=.002)$. Prior transplantation $(P=.02)$, age $(P=.03)$, and having therapy-related AML $(P=.05)$ were also associated with treatment-related mortality. Disease status $(P=.004)$ and performance status $(P=.007)$ were both strongly associated with risk of disease recurrence. Donor type was also associated $(P=.06)$ with risk of disease recurrence. Both disease status $(P=.001)$ and performance score $(P<.001)$ were strongly associated with progressionfree survival. Having an unrelated donor was also associated with decreased progression-free survival, but the association was less strong $(P=.02)$. Disease status, performance status, presence of comorbidities, and age were all associated with overall survival, but none of the $P$ values was significant. After relapse, many patients underwent 


\begin{tabular}{|c|c|c|c|c|}
\hline Disease & Comorbidities & Donor Type & $\begin{array}{l}\text { Day of } \\
\text { Death }\end{array}$ & Course \\
\hline Secondary AML & $\begin{array}{l}\text { Chronic renal failure, hypertension, fungal } \\
\text { sinusitis }\end{array}$ & HLA-identical sibling & 0 & Cardiac arrest during stem-cell infusion \\
\hline AML evolving from CMMOL & Acromegaly & HLA-identical sibling & 0 & $\begin{array}{l}\text { Anaphylactic reaction during conditioning, } \\
\text { with multiorgan failure }\end{array}$ \\
\hline Refractory AML & $\begin{array}{l}\text { CAD, history of CVA, DM, seizure } \\
\text { disorder, pacemaker }\end{array}$ & HLA-identical sibling & 22 & Pneumonia, TTP/HUS \\
\hline RAEB & Type II DM, CAD & MUD & 29 & $\mathrm{MI}, \mathrm{CHF}$ \\
\hline Refractory AML & $\begin{array}{l}\text { Adriamycin induced cardiomyopathy, } \\
\text { history of fungal pneumonia }\end{array}$ & MUD & 40 & VOD \\
\hline RARS & Active hepatitis with bridging fibrosis & Mismatched relative & 53 & Graft rejection \\
\hline Refractory AML & & MUD & 76 & Sudden cardiac death, TTP/HUS \\
\hline Refractory AML & Prior fungal pneumonia & Mismatched relative & 77 & Graft rejection \\
\hline Refractory AML & Prior nephrectomy & HLA-identical sibling & 95 & Dementia \\
\hline Refractory AML & & MUD & 107 & $\begin{array}{l}\text { Corticosteroid-refractory acute GVHD } \\
\text { grade } 2 \text { and sepsis }\end{array}$ \\
\hline $\begin{array}{l}\text { AML CR1, unfavorable } \\
\text { cytogenetics }\end{array}$ & Prior acute renal failure during induction & MUD & 113 & Grade 4 Acute GVHD \\
\hline RAEB & $\begin{array}{l}\text { Failed prior allogeneic transplantation, } \\
\text { restrictive lung disease }\end{array}$ & HLA-identical sibling & 122 & Multiorgan failure, $\mathrm{CMV}$ pneumonitis \\
\hline Refractory AML & $\begin{array}{l}\text { Restrictive lung disease due to } \\
\text { pulmonary hemorrhage }\end{array}$ & HLA-identical sibling & 131 & Pneumonia \\
\hline Secondary MDS after APL & Doxorubicin-related cardiomyopathy & MUD & 153 & CHF, cardiomyopathy \\
\hline AML, PR3 & & MUD & 263 & Pneumonia, chronic GVHD \\
\hline Secondary AML & $\begin{array}{l}\text { Breast cancer, CAD, history of CVA, } \\
\text { restrictive lung disease }\end{array}$ & MUD & 307 & Encephalopathy, myelitis \\
\hline \multicolumn{5}{|c|}{$\begin{array}{l}\text { Abbreviations: AML, acute myeloid leukemia; } \mathrm{CMMOL} \text {, chronic myelomonocytic leukemia; CAD, coronary artery disease; CVA, cerebrovascular accident; } \\
\mathrm{DM} \text {, diabetes mellitus; MI, myocardial infarction; CHF, congestive heart failure; VOD, veno-occlusive disease; TTP/HUS, thrombotic thrombocytopenic } \\
\text { purpura/hemolytic uremic syndrome; RAEB, refractory anemia with excess blasts; MDS, myelodysplastic syndrome; APL, acute promyelocyti } \\
\text { leukemia; MUD, matched unrelated donor; RARS, refractory anemia with ring sideroblasts; CR1, first complete remission; GVHD, graft-versus-host } \\
\text { disease; CMV, cytomegalovirus; PR, partial remission. }\end{array}$} \\
\hline
\end{tabular}

salvage chemotherapy and sometimes second transplantations. Such interventions likely influenced overall survival and may have diluted the impact of each of these potential predictors.

Figures 2 and 3 and Table 6 illustrate the effect of disease status and performance status on outcome. Patients with high-risk disease had a 39\% probability of disease recurrence, a 39\% probability of treatment-related mortality, and a probability of progression-free survival at 1 year of only $25 \%$. Similarly, patients with decreased performance status had $54 \%$ probability of treatment-related mortality, $40 \%$ probability of relapse, and probability of progressionfree survival at 1 year of only $6 \%$. In contrast, probability of progression-free survival for those with standard-risk disease or those with a normal performance score was $61 \%$ in each case.

\section{DISCUSSION}

Allogeneic transplantation is a curative treatment for patients with advanced leukemia or MDS. Complications of intensive myeloablative conditioning, relapse, and lack of donors have long limited its application to younger patients in excellent condition. Recent improvements, including better selection of unrelated donors, ${ }^{5}$ better management and prevention of infectious complications, ${ }^{35,36}$ the development of novel conditioning regimens, ${ }^{9,37,38}$ and newer methods of GVHD prophylaxis have generated considerable interest in extending the use of transplantation to older and less fit patients. ${ }^{1-3}$

In our previous studies of the fludarabine and melphalan regimen, we observed excellent engraftment, reasonable disease control, but excessive toxicity and GVHD. ${ }^{11}$ To reduce toxicity and GVHD, we omitted methotrexate in the current study and replaced it with in vivo alemtuzumab (Campath Ilex Pharmaceuticals, San Antonio, TX). Alemtuzumab is a monoclonal antibody directed against CD52, an antibody widely expressed on B cells, T cells, and natural killer cells. Immunoglobulin $\mathrm{M}$ antibodies, IgG antibodies, and most recently, humanized IgG antibodies (alemtuzumab) against CD52 have been used as in vitro T-cell-depleting agents with variable success rates. ${ }^{39}$ The British Cooperative Group were the first to report a combination of fludarabine, melphalan, and in vivo alemtuzumab for conditioning in allogeneic transplantation and have studied its use mainly in lymphoid malignancies. ${ }^{20,21}$ They used single-agent cyclosporine 

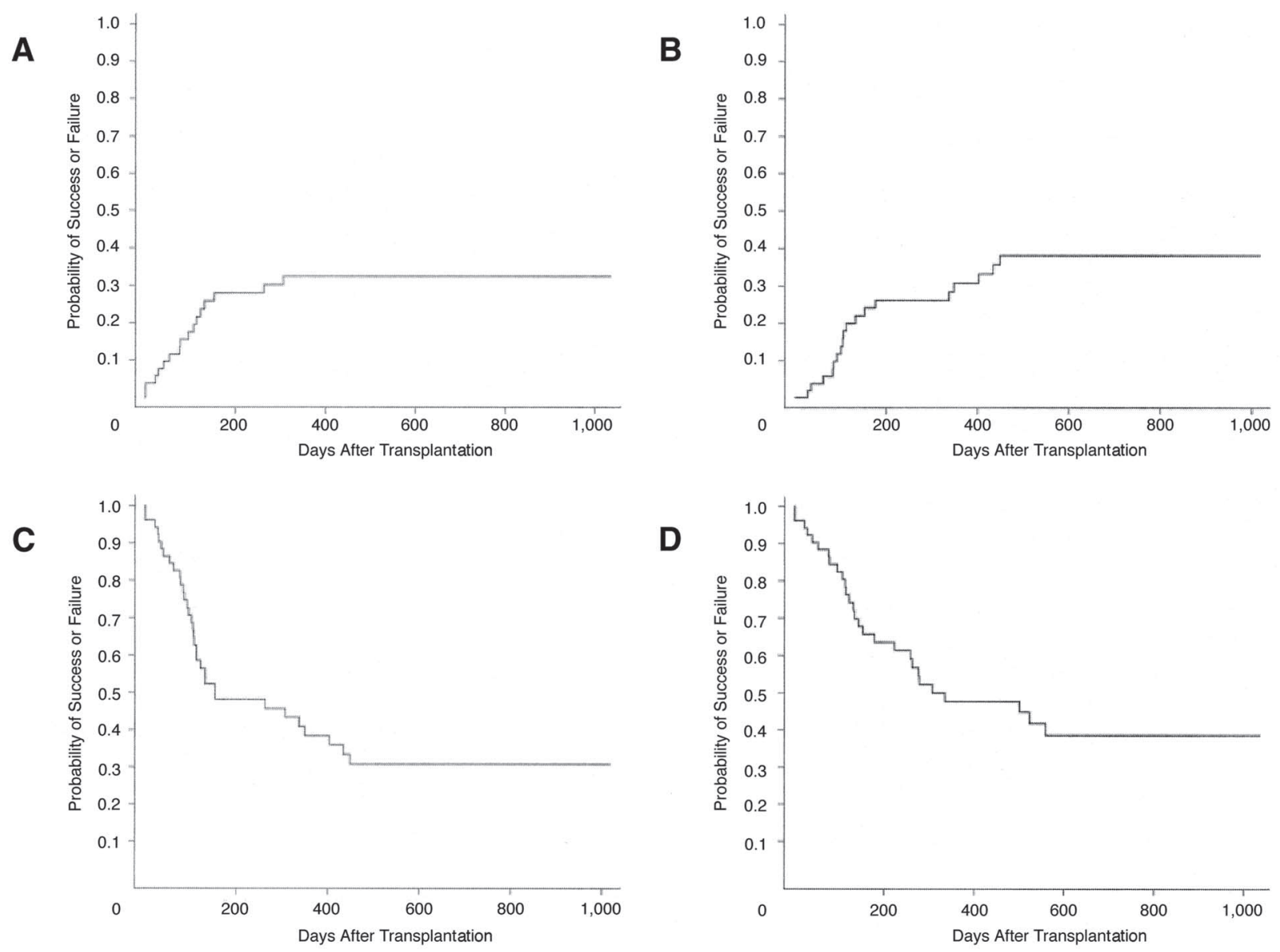

Fig 2. (A) Treatment-related mortality; (B) relapse rate; (C) progression-free survival; and (D) survival of all patients.

for post-transplantation GVHD prophylaxis and demonstrated a high rate of engraftment, acceptable toxicity, and in most malignancies, relatively low rates of treatmentrelated mortality. ${ }^{20-22}$ They also reported a low incidence of acute and in particular of chronic GVHD using both matched-related and matched-unrelated allografts. We used nearly the same conditioning regimen but substituted tacrolimus for cyclosporine. Another major difference was our use of aggressive CMV prophylaxis with pretransplantation ganciclovir and post-transplantation high-dose valacyclovir in the majority of patients. ${ }^{26}$ This resulted in a cumulative incidence of CMV reactivation of only $29 \%$ and possibly a reduction of adenovirus reactivation. ${ }^{40-42}$

Here we report our results in AML and MDS. Our patient population had many unfavorable clinical features. The majority of patients had refractory leukemia or MDS with an increased percentage of blasts. Even the so-called standard-risk patients had unfavorable types of leukemia or
MDS. In addition to high-risk disease, the patients were at high risk of transplantation complications, making standard ablative transplantation a relative contraindication for the majority. More than one fourth had experienced disease relapse after a prior transplantation and others had suffered previous fungal infections, had serious comorbidities, or had a decreased performance status. More than half received transplants from unrelated donors or from mismatched related donors. Finally, the median age of 52 years was older than in most other studies of novel conditioning regimens and older than in our own previous studies. Given these many adverse features, the 1-year survival of $48 \%$ overall and progression-free survival of $38 \%$ are encouraging.

Additional analysis of these data engenders several observations of interest. First, we confirm the British report on high rates of engraftment, relatively minimal regimen-related toxicity, and low incidence and severity of acute and chronic 


\begin{tabular}{|lrr|}
\hline \multicolumn{3}{|c|}{ Table 3. Outcome Probabilities } \\
\hline \multicolumn{1}{c|}{ Outcome } & Probability (\%) & $95 \% \mathrm{Cl}$ \\
\hline Treatment-related mortality* & 17 & 9 to 29 \\
Day 100 & 28 & 16 to 41 \\
Day 200 & 33 & 20 to 46 \\
1 year & 33 & 20 to 46 \\
2 years & & \\
Relapse* & 12 & 5 to 23 \\
Day 100 & 27 & 16 to 40 \\
Day 200 & 32 & 19 to 45 \\
1 year & 40 & 25 to 54 \\
2 years & & \\
Survivalt & 83 & 69 to 91 \\
Day 100 & 64 & 49 to 75 \\
Day 200 & 33 to 61 \\
1 year & 48 & 24 to 53 \\
2 years & 39 & \\
Progression-free survivalt & & 56 to 81 \\
Day 100 & 71 & 34 to 61 \\
Day 200 & 25 to 52 \\
1 year & 48 & 18 to 45 \\
2 years & 38 & \\
*Cumulative incidence. & 31 & \\
tKaplan-Meier estimate. & & \\
& & \\
\hline
\end{tabular}

GVHD. In addition, similar to other recent reports, ${ }^{5,43-45}$ related and unrelated donor transplantation appeared to result in similar outcomes. Still, even from our preliminary experi- ence, it is obvious that the risk for chronic GVHD remains higher after matched unrelated than after HLA-identical sibling transplantation, and in multivariate analysis, some impact of donor type on progression-free survival remained. Recipient age and Charlson comorbidity score are probably less important in predicting outcome of transplantation and were only moderately associated with outcome. ${ }^{9,46}$

Pretransplantation disease status and performance status were the major predictors for progression-free and overall survival. The outcomes for patients with standardrisk disease were excellent. Among 20 such patients, there were only three recurrences and four treatment-related deaths, resulting in a progression-free survival rate of $61 \%$ at 1 year, with no recurrences beyond 1 year. This regimen is therefore curative for a high fraction of AML/MDS patients with standard-risk disease and, because of the low risk of severe GVHD, may be preferable to non-T-cell depleted transplantation. Other studies in younger standard-risk patients with T-cell depletion and more ablative regimens have yielded similar results. ${ }^{47-52}$ In contrast, Bacigalupo et $\mathrm{al}^{19}$ showed in a randomized study that non-T-cell depleted transplantation is associated with a prolonged and persistent risk of morbidity and mortality, related to GVHD and bronchiolitis obliterans. Our data can also be compared with those of the M.D. Anderson group, which obtained (with a busulfan and fludarabine regimen) approximately

\begin{tabular}{|c|c|c|c|c|c|c|c|c|}
\hline \multirow[b]{2}{*}{ Parameter } & \multicolumn{2}{|c|}{$\begin{array}{c}\text { Treatment } \\
\text { Related-Mortality }\end{array}$} & \multicolumn{2}{|c|}{ Relapse } & \multicolumn{2}{|c|}{ Progression-Free Survival } & \multicolumn{2}{|c|}{ Overall Survival } \\
\hline & Relative Risk & $P$ & Relative Risk & $P$ & Relative Risk & $P$ & Relative Risk & $P$ \\
\hline \multicolumn{9}{|l|}{ Disease status } \\
\hline Standard risk & 1 & .16 & 1 & .01 & 1 & .003 & 1 & .02 \\
\hline High risk & 2.26 & & 5.46 & & 3.66 & & 2.91 & \\
\hline Age, per decade & 1.05 & .04 & 1.00 & .92 & 1.02 & .18 & 1.04 & .02 \\
\hline \multicolumn{9}{|l|}{ Performance status } \\
\hline 0 & 1 & .01 & 1 & .01 & 1 & $<.001$ & 1 & .002 \\
\hline $1-3$ & 4.43 & & 4.09 & & 5.12 & & 3.23 & \\
\hline \multicolumn{9}{|l|}{ Diagnosis } \\
\hline AML & 1 & .62 & 1 & .72 & 1 & .51 & 1 & .80 \\
\hline MDS & 1.33 & & 1.22 & & 1.31 & & 1.12 & \\
\hline \multicolumn{9}{|l|}{ Therapy-related myeloid leukemia } \\
\hline No & 1 & .82 & 1 & .23 & 1 & .26 & 1 & .34 \\
\hline Yes & 1.16 & & 2.03 & & 1.63 & & 1.56 & \\
\hline \multicolumn{9}{|l|}{ Comorbidity } \\
\hline No & 1 & .03 & 1 & .19 & 1 & .01 & 1 & .001 \\
\hline Yes, $>0$ & 3.03 & & 1.94 & & 2.52 & & 3.52 & \\
\hline \multicolumn{9}{|l|}{ Prior transplantation } \\
\hline No & 1 & .15 & 1 & .60 & 1 & .25 & 1 & .07 \\
\hline Yes & 2.11 & & 1.35 & & 1.59 & & 2.14 & \\
\hline \multicolumn{9}{|l|}{ Donor type } \\
\hline HLA-identical sibling & 1 & & 1 & & 1 & & 1 & \\
\hline One-antigen mismatched related & 2.23 & .33 & .81 & .85 & 1.46 & .55 & 1.25 & .77 \\
\hline Unrelated & 1.31 & .62 & 1.36 & .54 & 1.48 & .29 & 1.54 & .28 \\
\hline
\end{tabular}

Abbreviations: AML, acute myeloid leukemia; MDS, myelodysplastic syndrome. 


\begin{tabular}{|c|c|c|c|c|c|c|c|c|}
\hline \multirow[b]{2}{*}{ Parameter } & \multicolumn{2}{|c|}{$\begin{array}{l}\text { Treatment-Related } \\
\text { Mortality }\end{array}$} & \multicolumn{2}{|c|}{ Relapse } & \multicolumn{2}{|c|}{ Progression-Free Survival } & \multicolumn{2}{|c|}{ Overall Survival } \\
\hline & Relative Risk & $\bar{P}$ & Relative Risk & $P$ & Relative Risk & $P$ & Relative Risk & $P$ \\
\hline Disease status & - & - & 6.98 & .004 & 4.57 & .001 & 2.54 & 0.04 \\
\hline Age, per decade & 1.08 & .03 & - & - & - & - & 1.03 & 0.07 \\
\hline Performance status & 6.98 & .002 & 4.24 & .007 & 5.49 & $<.001$ & 2.14 & 0.07 \\
\hline Diagnosis & - & - & - & - & - & - & - & - \\
\hline Secondary leukemia/MDS & 0.24 & .05 & - & - & - & - & - & - \\
\hline Comorbidity & - & - & - & - & - & - & 2.54 & 0.02 \\
\hline Prior transplantation & 5.74 & .01 & - & - & - & - & - & - \\
\hline \multicolumn{9}{|l|}{ Donor type } \\
\hline HLA-identical sibling & & & 1 & & 1 & & & \\
\hline One-antigen mismatched related & - & - & 1.67 & .64 & 2.89 & .11 & - & - \\
\hline Unrelated & - & - & 2.76 & .06 & 2.65 & .02 & - & - \\
\hline
\end{tabular}

Abbreviation: MDS, myelodysplastic syndrome.

$75 \%$ progression-free survival at 1 year among patients who underwent transplantation in remission, but with a more than $50 \%$ cumulative incidence of chronic GVHD. ${ }^{53}$
Our series had a much higher proportion of patients receiving unrelated-donor transplantation and a lower risk of chronic GVHD.

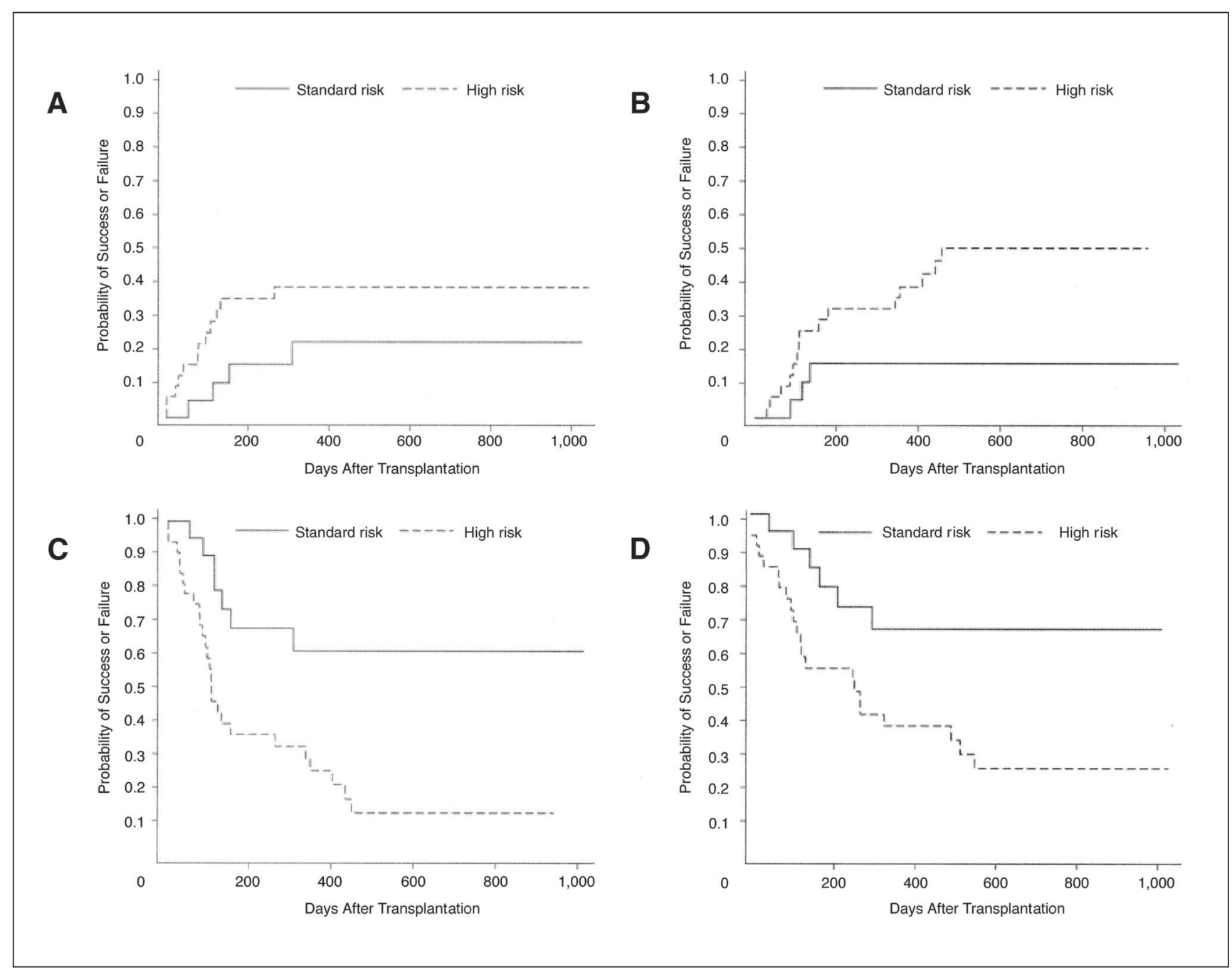

Fig 3. (A) Treatment-related mortality; (B) relapse rate; (C) progression-free survival; and (D) survival; high-risk versus standard-risk patients. 


\begin{tabular}{|c|c|c|c|c|c|c|c|c|}
\hline \multirow[b]{3}{*}{ Outcomes } & \multicolumn{4}{|c|}{ Disease Status } & \multicolumn{4}{|c|}{ PS } \\
\hline & \multicolumn{2}{|c|}{ Standard Risk } & \multicolumn{2}{|c|}{ High Risk } & \multicolumn{2}{|c|}{$P S=0$} & \multicolumn{2}{|c|}{$P S \geq 1$} \\
\hline & $\%$ & $95 \% \mathrm{Cl}$ & $\%$ & $95 \% \mathrm{Cl}$ & $\%$ & $95 \% \mathrm{Cl}$ & $\%$ & $95 \% \mathrm{Cl}$ \\
\hline Treatment-related mortality* & 22 & 7 to 44 & 39 & 19 to 52 & 18 & 7 to 35 & 54 & 30 to 73 \\
\hline Relapse* & 16 & 4 to 35 & 39 & 22 to 55 & 25 & 11 to 41 & 40 & 19 to 60 \\
\hline Survivalt & 66 & 39 to 83 & 37 & 21 to 54 & 64 & 44 to 79 & 23 & 8 to 44 \\
\hline Progression-free survivalt & 61 & 35 to 79 & 25 & 12 to 42 & 61 & 40 to 76 & 6 & 0.5 to 24 \\
\hline
\end{tabular}

Patients with active leukemia or MDS with increased blasts fared poorly (Fig 3). Their progression-free survival rate at 200 days after transplantation was 38\% (95\% CI, 21\% to $55 \%$ ) and at 1 year it was $25 \%$ (95\% CI, $12 \%$ to $42 \%)$. In light of the extremely poor prognosis of this group, the regi- men potentially provided prolonged palliation to approximately one fourth of the high-risk patients. However, few were cured; among seven high-risk patients who were still in remission 1 year after transplantation, four had a recurrence during the second year of follow-up. Classic myeloablative

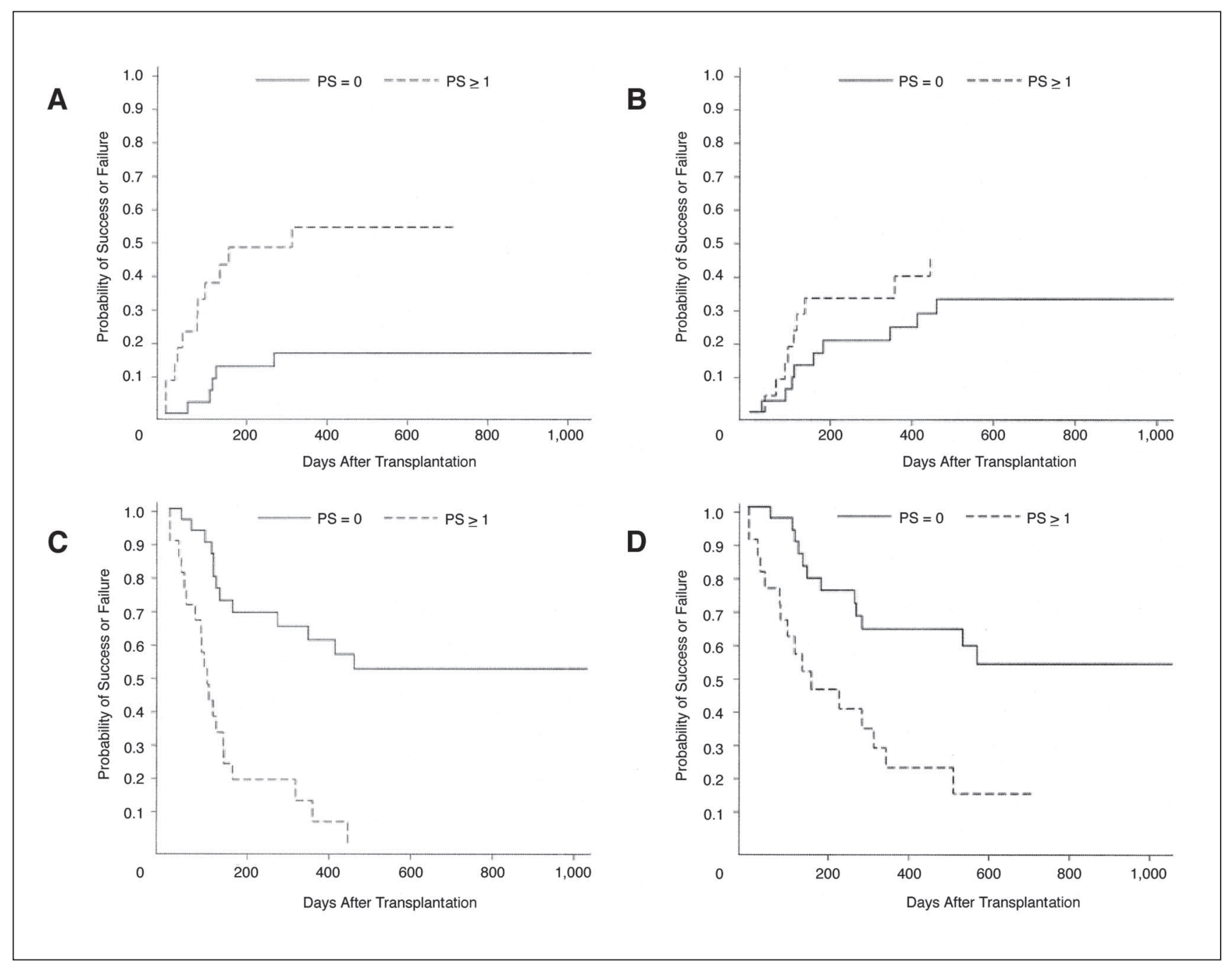

Fig 4. (A) Treatment-related mortality; (B) relapse rate; (C) progression-free survival; and (D) survival: performance score (PS) 0 v 1 to 3. 
conditioning regimens are similarly associated with high rates of disease recurrence and treatment-related mortality in patients with high-risk disease, and do not represent a better choice. ${ }^{54,55}$ For such patients, alternative approaches including investigational therapies need to be explored, and when such patients are counseled to undergo transplantation, the limited expectation of benefit must be clarified.

The most important predictor of treatment-related mortality was performance status, which was also a major predictor of progression-free survival and of overall survival. ${ }^{9,46}$ Even modest decreases in performance status led to major differences in outcome (Fig 4). It is likely that assessment of performance status captures the impact of leukemia and of certain comorbidities better than currently available scoring systems such as the Charlson score. Pending the development of better instruments, data on performance status should be routinely and ideally prospectively included in transplantation trials.

In summary, the fludarabine and melphalan regimen when combined with in vivo alemtuzumab is a promising transplantation regimen for patients with AML and MDS and low tumor burden; it demonstrates excellent disease control and high tolerability. The effective T-cell depletion greatly reduces the risk of GVHD and thus attenuates the impact of age and comorbidities on TRM. Stringent antiviral prophylaxis may have contributed to the relatively low rate of viral reactivation and opportunistic infections. ${ }^{42}$ For patients with active disease, this regimen provides modest palliation, but long-term disease control is poor. Despite the low incidence of GVHD, the management of patients with decreased performance status also poses considerable problems. In this difficult patient group, our reduced-intensity conditioning was still associated with considerable nonrelapse mortality, and other approaches need to be investigated.

\section{Acknowledgment}

We thank Theodore Karrison, PhD, for help in the statistical analysis.

\section{Authors' Disclosures of Potential Conflicts of Interest}

Although all authors have completed the disclosure declaration, the following author or their immediate family members has indicated a financial interest. No conflict exists for drugs or devices used in a study if they are not being evaluated as part of the investigation. For a detailed description of the disclosure categories, or for more information about ASCO's conflict of interest policy, please refer to the Author Disclosure Declaration and the Disclosures of Potential Conflicts of Interest section in Information for Contributors.

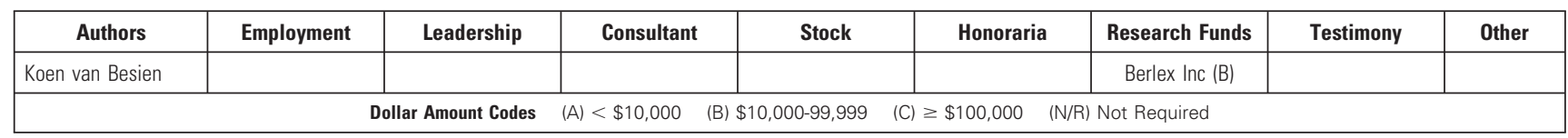

\section{REFERENCES}

1. van Besien K, Artz A, Stock W: Unrelated donor transplantation over the age of 55. Are we merely getting (b)older? Leukemia 19:31-33, 2005

2. Shimoni $A$, Kroger $N$, Zabelina $T$, et al: Hematopoietic stem-cell transplantation from unrelated donors in elderly patients lage $>55$ years) with hematologic malignancies: Older age is no longer a contraindication when using reduced intensity conditioning. Leukemia 19:7-12, 2005

3. Wong $\mathrm{R}$, Giralt $\mathrm{SA}$, Martin $\mathrm{T}$, et al: Reduced-intensity conditioning for unrelated donor hematopoietic stem cell transplantation as treatment for myeloid malignancies in patients older than 55 years. Blood 102:3052-3059, 2003

4. Bensinger WI, Martin PJ, Storer B, et al: Transplantation of bone marrow as compared with peripheral-blood cells from HLA-identical relatives in patients with hematologic cancers. N Engl J Med 344:175-181, 2001

5. Flomenberg N, Baxter-Lowe LA, Confer D, et al: Impact of HLA class I and class II high resolution matching on outcomes of unrelated donor bone marrow transplantation: HLA-C mismatching is associated with a strong adverse effect on transplant outcome. Blood 104:19231930, 2004
6. Kernan NA, Bartsch G, Ash RC, et al: Analysis of 462 transplantations from unrelated donors facilitated by the National Marrow Donor Program. N Engl J Med 328:593-602, 1993

7. de Witte T, Hermans J, Vossen J, et al: Haematopoietic stem cell transplantation for patients with myelo-dysplastic syndromes and secondary acute myeloid leukaemias: A report on behalf of the Chronic Leukaemia Working Party of the European Group for Blood and Marrow Transplantation (EBMT). Br J Haematol 110:620630, 2000

8. Castro-Malaspina $H$, Harris RE, Gajewski J, et al: Unrelated donor marrow transplantation for myelodysplastic syndromes: Outcome analysis in 510 transplants facilitated by the National Marrow Donor Program. Blood 99:1943-1951, 2002

9. Sorror ML, Maris MB, Storer B, et al: Comparing morbidity and mortality of HLA-matched unrelated donor hematopoietic cell transplantation after nonmyeloablative and myeloablative conditioning: Influence of pretransplantation comorbidities. Blood 104:961-968, 2004

10. van Besien K, Devine S, Wickrema A, et al: Fludarabine melphalan is a suitable alternative to fludarabine-TBI based conditioning for allogeneic transplantation in patients with advanced hematologic malignancies. Hematol J 3:78a 2002 (suppl 1; abstr 580)
11. van Besien $K$, Devine $S$, Wickrema $A$, et al: Regimen-related toxicity after fludarabinemelphalan conditioning: A prospective study of 31 patients with hematologic malignancies. Bone Marrow Transplant 32:471-476, 2003

12. Van Besien KW, Demuynck $H$, LeMaistre $\mathrm{CF}$, et al: High dose melphalan allows durable engraftment of allogeneic bone marrow. Bone Marrow Transplant 15:321-323, 1995

13. Singhal S, Powles R, Treleaven J, et al: Melphalan alone prior to allogeneic bone marrow transplantation from HLA-identical sibling donors for hematologic malignancies: Alloengraftment with potential preservation of fertility in women Bone Marrow Transplant 18:1049-1055, 1996

14. Gandhi V, Plunkett W: Cellular and clinical pharmacology of fludarabine. Clin Pharmacokinet 41:93-103, 2002

15. Essell JH, Thompson JM, Harman GS, et al: Marked increase in veno-occlusive disease of the liver associated with methotrexate use for graft-versus-host disease prophylaxis in patients receiving busulfan/cyclophosphamide. Blood 79: 2784-2788, 1992

16. Dulley FL, Kanfer EJ, Appelbaum FR, et al: Venocclusive disease of the liver after chemoradiotherapy and autologous bone marrow transplantation. Transplantation 43:870-873, 1987

17. Styler MJ, Crilley P, Biggs J, et al: Hepatic dysfunction following busulfan and cyclophos- 
phamide myeloablation: A retrospective, multicenter analysis. Bone Marrow Transplant 18: 171-176, 1996

18. Cutler C, Li S, Kim H-S, et al: Oral mucositis incidence and severity after methotrexate and non-methotrexate containing GVHD prophylaxis. Blood 104:104a, 2004 (suppl 1; abstr 351)

19. Bacigalupo A, Vignola M, Lamparelli $T$, et al: Long term follow up of two randomized trials on antithymocyte globulin (ATG) for GvHD prophylaxis in unrelated donor transplants: Chronic GvHD, bronchiolitis and quality of life. Blood 104:128a, 2004 (suppl 1; abstr 638)

20. Chakraverty R, Peggs $K$, Chopra R, et al: Limiting transplantation-related mortality following unrelated donor stem cell transplantation by using a nonmyeloablative conditioning regimen. Blood 99:1071-1078, 2002

21. Kottaridis PD, Milligan DW, Chopra R, et al: In vivo CAMPATH-1H prevents graft-versushost disease following nonmyeloablative stem cell transplantation. Blood 96:2419-2425, 2000

22. Morris $E$, Thomson $K$, Craddock $C$, et al: Outcome following alemtuzumab (CAMPATH-1H)containing reduced intensity allogeneic transplant regimen for relapsed and refractory nonHodgkin's lymphoma (NHL). Blood 104:38653871, 2004

23. Greenberg P, Cox C, LeBeau MM, et al: International scoring system for evaluating prognosis in myelodysplastic syndromes. Blood 89: 2079-2088, 1997

24. Charlson M, Szatrowski TP, Peterson J, et al: Validation of a combined comorbidity index. J Clin Epidemiol 47:1245-1251, 1994

25. Verma A, Devine S, Morrow M, et al: Low incidence of CMV viremia and disease after allogeneic peripheral blood stem cell transplantation: Role of pretransplant ganciclovir and posttransplant acyclovir. Bone Marrow Transplant 31:813-816, 2003

26. Ljungman $P$, De la Camara $R$, Milpied $N$, et al: Randomized study of valacyclovir as prophylaxis against cytomegalovirus reactivation in recipients of allogeneic bone marrow transplants. Blood 99:3050-3056, 2002

27. Nichols WG, Price TH, Gooley $T$, et al: Transfusion-transmitted cytomegalovirus infection after receipt of leukoreduced blood products. Blood 101:4195-4200, 2003

28. Przepiorka D, Weisdorf D, Martin $P$, et al: Consensus conference on GVHD grading. Bone Marrow Transplant 15:825-828, 1995

29. Bartholomew A, Sher D, Sosler S, et al: Stem cell transplantation eliminates alloantibody in a highly sensitized patient. Transplantation 72:1653-1655, 2001

30. Kaplan EL, Meier P: Nonparametric estimation from incomplete observations. J Am Stat Assoc 53:457-481, 1958

31. Gooley TA, Leisenring W, Crowley J, et al: Estimation of failure probabilities in the presence of competing risks: New representations of old estimators. Stat Med 18:695-706, 1999

32. Chappell R: Letter to the editor. Int J Radiat Oncol Biol Phys 36:988-989, 1996

33. Klein JP, Rizzo JD, Zhang MJ, et al: Statistical methods for the analysis and presentation of the results of bone marrow transplants. Part I: Unadjusted analysis. Bone Marrow Transplant 28:909-915, 2001

34. van Besien K, Smith S, Anastasi J, et al: Irreversible myelosuppression after fludarabinemelphalan conditioning: Observations in patients with graft rejection. Blood 103:4373-4374, 2004

35. Wingard JR, Leather $H$ : A new era of antifungal therapy. Biol Blood Marrow Transplant 10:73-90, 2004

36. Boeckh M, Nichols WG, Papanicolaou G, et al: Cytomegalovirus in hematopoietic stem cell transplant recipients: Current status, known challenges, and future strategies. Biol Blood Marrow Transplant 9:543-558, 2003

37. Slavin S, Nagler A, Naparstek E, et al: Nonmyeloablative stem cell transplantation and cell therapy as an alternative to conventiona bone marrow transplantation with lethal cytoreduction for the treatment of malignant and nonmalignant hematologic diseases. Blood 91:756763, 1998

38. Giralt S, Thall PF, Khouri I, I, et al: Melphalan and purine analog-containing preparative regimens: Reduced- intensity conditioning for patients with hematologic malignancies undergoing allogeneic progenitor cell transplantation. Blood 97:631637, 2001

39. Hale G, Zhang MJ, Bunjes D, et al: Improving the outcome of bone marrow transplantation by using CD52 monoclonal antibodies to prevent graft-versus-host disease and graft rejection. Blood 92:4581-4590, 1998

40. Avivi I, Chakrabarti S, Milligan DW, et al: Incidence and outcome of adenovirus disease in transplant recipients after reduced-intensity conditioning with alemtuzumab. Biol Blood Marrow Transplant 10:186-194, 2004

41. Chakrabarti S, Mackinnon S, Chopra R, et al: High incidence of cytomegalovirus infection after nonmyeloablative stem cell transplantation: Potential role of Campath-1 $\mathrm{H}$ in delaying immune reconstitution. Blood 99:4357-4363, 2002

42. Kline J, Pollyea D, Larson RA, et al: Ganciclovir and high-dose valacyclovir prevent cytomegalovirus reactivation in patients receiving allogeneic stem cell transplants with Campath-1H based conditioning regimens. Biol Blood Marrow Transplant 11:94, 2005 (suppl 1; abstr 277)

43. Chalandon $Y$, Halter J, Guengoer $T$, et al: Impact of molecular HLA-matching for allogeneic transplantation from unrelated donors. Blood 104:280a, 2004 (abstr 979)

44. Fillion A, Loiseau P, Rocha V, et al: Decreased transplant related mortality and better survival in HLA matched (12/12 A, B, C, DRB1,
DQB1, DBP1) unrelated bone marrow trans plants. Blood 104:280a, 2004 (abstr 977)

45. Yakoub-Agha I, Boiron J-M, Michallet M, et al: Genoidentical donor versus A, B, Cw, Dr, DQ, HLA allelic matched unrelated donor for stem cell transplantation in patients with standard risk hematological malignancy. Blood 104: 279a, 2004 (abstr 976)

46. Pollyea D, Artz AS, Stock W, et al: Clinical predictors of transplant related mortality after reduced intensity allogeneic hematopoietic transplantation. Blood 104:324a, 2004 (abstr 1145)

47. Deeg HJ, Appelbaum FR, Storer B, et al: Reduced incidence of acute and chronic graftversus-host disease (GvHD) without increased relapse in patients with high-risk myeloid disorders given thymoglobulin (THY) as part of the transplant conditioning regimen: A dose-finding study. Blood 104:569a, 2004 (abstr 181)

48. Papadopoulos EB, Carabasi MH, CastroMalaspina $H$, et al: T-cell-depleted allogeneic bone marrow transplantation as postremission therapy for acute myelogenous leukemia: Freedom from relapse in the absence of graft-versushost disease. Blood 91:1083-1090, 1998

49. Soiffer RJ, Fairclough D, Robertson M, et al: CD6-depleted allogeneic bone marrow transplantation for acute leukemia in first complete remission. Blood 89:3039-3047, 1997

50. Aversa F, Terenzi A, Carotti A, et al: Improved outcome with T-cell-depleted bone marrow transplantation for acute leukemia. J Clin Oncol 17:1545-1550, 1999

51. Marks DI, Bird JM, Vettenranta K, et al: T cell-depleted unrelated donor bone marrow transplantation for acute myeloid leukemia. Biol Blood Marrow Transplant 6:646-653, 2000

52. Chakrabarti S, Marks DI: Should we T cell deplete sibling grafts for acute myeloid leukaemia in first remission? Bone Marrow Transplant 32:1039-1050, 2003

53. de Lima M, Couriel D, Thall PF, et al: Once-daily intravenous busulfan and fludarabine: Clinical and pharmacokinetic results of a myeloablative, reduced-toxicity conditioning regimen for allogeneic stem cell transplantation in $\mathrm{AML}$ and MDS. Blood 104:857-864, 2004

54. Sierra J, Storer B, Hansen JA, et al: Transplantation of marrow cells from unrelated donors for treatment of high-risk acute leukemia: The effect of leukemic burden, donor HLA matching, and marrow cell dose. Blood 89:4226-4235, 1997

55. Kebriaei $P$, Kline J, Stock $W$, et al: Impact of disease burden at time of allogeneic stem cell transplantation in adults with acute myeloid leukemia and myelodysplastic syndromes. Bone Marrow Transplant 35:965-970, 2005 